\title{
Impact of Osteoarthritis on Balance, Perceived Fear of fall and Quality of Life
}

\author{
Garima Gupta ${ }^{1^{*}}$ and Ankit Sharma ${ }^{2}$ \\ ${ }^{1}$ Krupanidhi college of Physiotherapy, Bangalore, India \\ ${ }^{2}$ Saaii College of medical science and technology, India
}

Submission: April 11, 2018; Published: May 22, 2018

*Corresponding author: Garima Gupta, Associate professor, Krupanidhi college of Physiotherapy, Bangalore, India, Email: gariace@gmail.com

\section{Introduction}

Osteoarthritis $(\mathrm{OA})$ is the commonest form of degenerative inflammatory joint disease, characterized by articular cartilage degradation [1]. Hereditary, developmental, metabolic, or mechanical causes may initiate the degenerative process; bone surfaces become less well protected by cartilage, bone may be exposed and damaged. It may results in joint pain, tenderness, stiffness, locking, and restricted or loss of mobility. As a result of decreased movement secondary to pain, regional muscles mayget atrophied, and ligaments may become more lax [2]. Individuals with OA suffer progressive loss of function, displaying increasing dependency in walking, stair climbing and other lower extremity tasks. With advancing age osteoarthritis (OA) of the hips and the knees is a major disabling disorder due to its restricting effect on mobility. As the population ages worldwide, OA has become a serious health threat and economical burden to many countries. It is estimated that almost $18 \%$ of women and $10 \%$ of men 60 years of age and older have symptomatic OA. [2-4].
Balance is an integral component of mobility and many activities of daily living. It is a complex function involving numerous neuromuscular processes $[3,5]$. Control of balance is dependent upon sensory input from the vestibular, visual and somato-sensory systems. Effective control of balance relies both on accurate sensory input and on a timely response of strong muscles. Control of balance is essential in all static and dynamic postures situations [6]. Various researches have documented that balance impairments may results in an increased risk of falls and poorer mobility measures in the elderly population, which could lead to ADL restriction and social isolation [7]. For populations with chronic disease, measurement of QOL provides a meaningful way to determine the impact of health care when cure is not possible. Over the past 20 years, hundreds of instruments have been developed that purport to measure QOL [8].

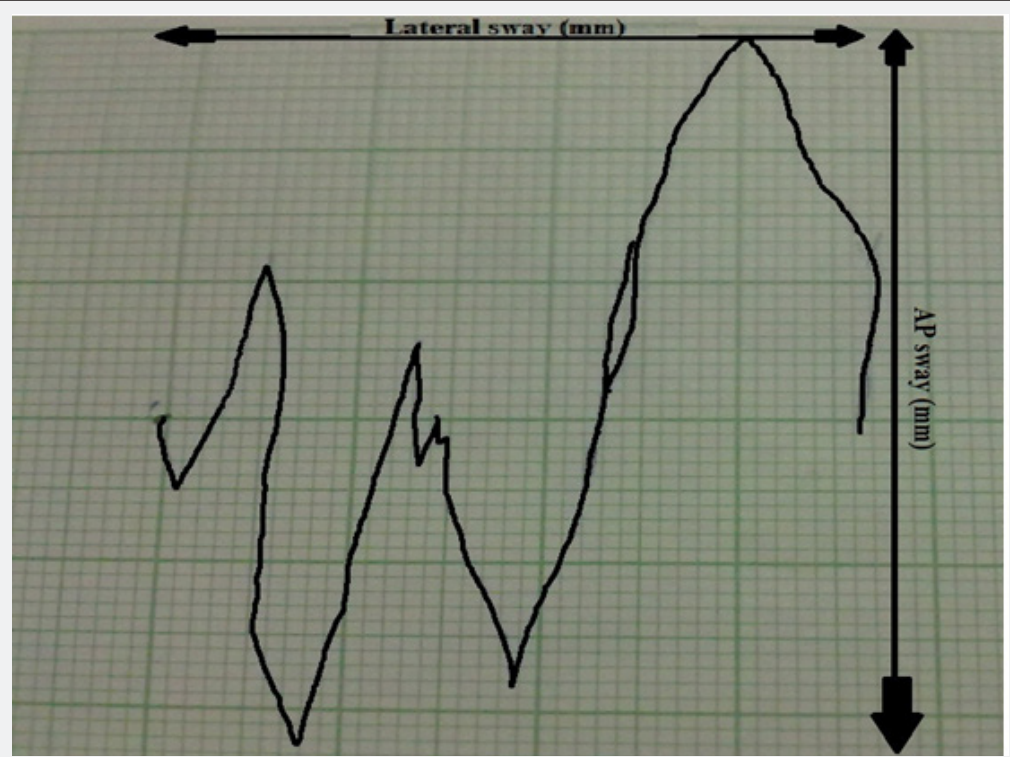

Figure 1: Calculation of lateral and Anterio posterior body sway from pen tracing. 


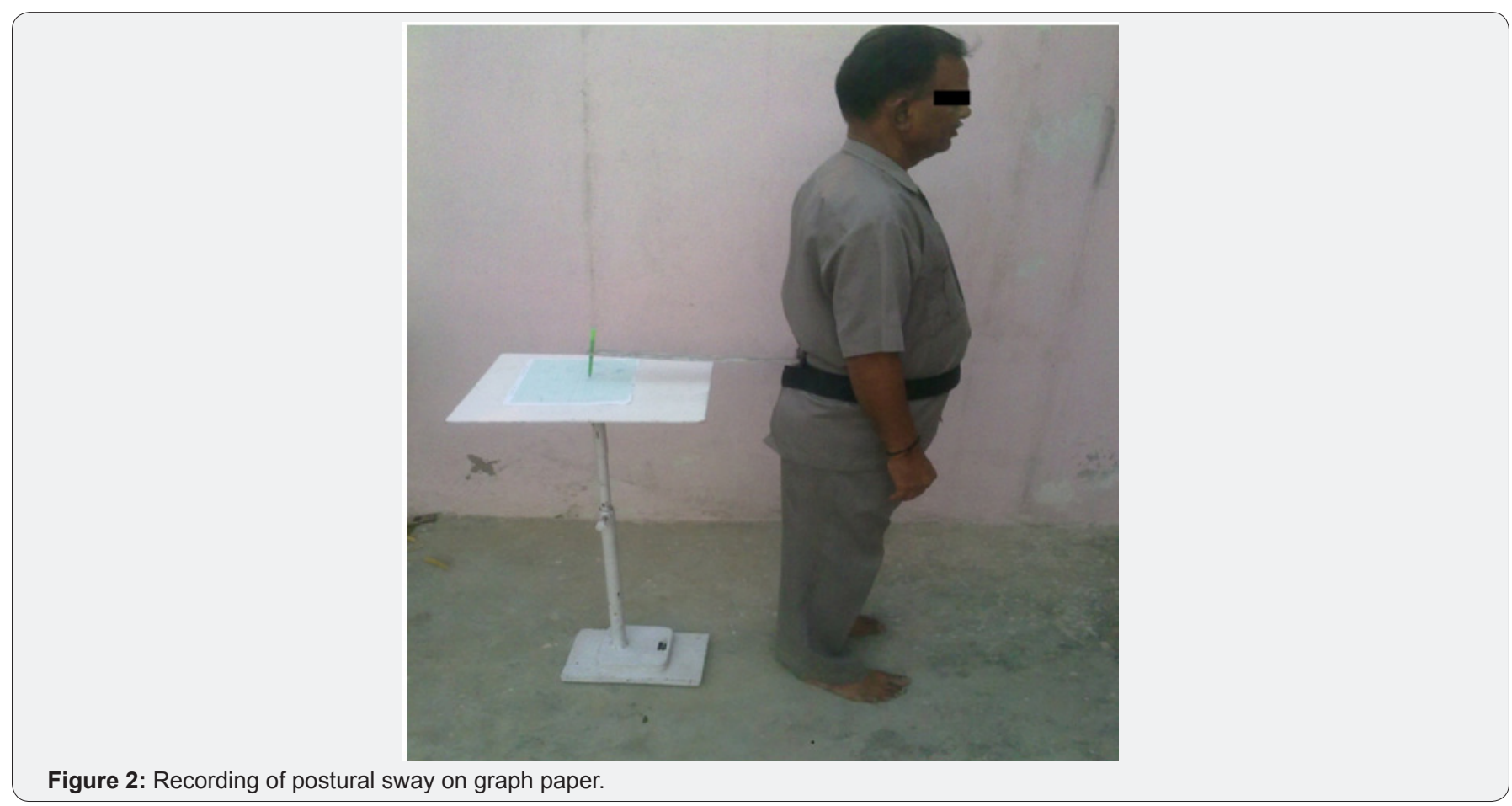

There are various studies on balance deficits in elderly population but much less has been studied about the presence of balance deficits in osteoarthritic population and if studied most of the studies used force platform, or balance master was as a tool. Postural sway is often used as an indicator of static standing balance where bodily movement in both the anterioposterior (AP) and lateral/ transverse direction are analyzed [3] (Figure 1). Postural sway-meter is a cost effective tool for the assessment of postural sway. It is a reliable tool for assessing postural sway and discriminates between performance of young and older people across multiple sensory conditions [6] (Figure 2). Present study is designed to use cost effective clinical tools for assessing the balance in people with osteoarthritis. The intent of this study is to study the impact of knee OA on balance. Present study also aimed to study and correlates the impact of severity of knee disability with perceived fear of fall, previous number of falls and quality of life in people of 50-70 years of age group. We also aimed to study the affect of balance deficits on quality of life and the effect of previous falls on person's perceived fear of fall.

We hypothesized that the osteoarthritis group will have more balance deficits as compared to the control group. We also hypothesized that various degrees of knee disability will have significant impact on number of falls, perceived fear of fall and the quality of life in people of 50-70 years of age group. Previous falls in will have an impact of their perceived fear of fall.

\section{Method}

This study was an experimental study. The study was approved by research committee of Saaii College of Medical Science and Technology, Kanpur University, India. The subjects who were ready to participate were recruited from the orthopedics department of government Lala Lajpat Rai Hospital (LLR/ Hallet) Kanpur, India. Subjects who fulfilled the inclusion and exclusion criteria were selected. Diagnosis of OA was confirmed by orthopaedician of Lala Lajpat Rai Hospital based on the guidelines of EULAR 2009: The Annual European Congress of Rheumatology. A sample of 60 people (male and females) of 50-70 years took part in the present study $[1,4]$. People with OA were included if they had knee pain on most days of previous month (average pain $>3 \mathrm{~cm}$ on a $10 \mathrm{~cm}$ visual analogue scale (VAS) [3]. People who were experiencing pain or difficulty while getting up from sitting or climbing stairs were selected [5].

People having MMSE SCORE $\geq 24$ were included [6]. People who were $\leq 50$ or $\geq 70$ years of age were not considered for the study. Participants those who were having neurological, cardiovascular problems were excluded from the study. People who took physiotherapy for treatment of the knee (previous 12 month), knee surgery (previous 12 months), past history of lower limb joint replacement, or intra articular steroid injection (previous 6 months), systemic arthritic condition, or severe medical condition precluding safe testing were excluded [5] Control participants were excluded if they have any sign and symptoms of $\mathrm{OA} \&$ if they reported any deformity in knee or any lower limb pathology or any injury to pain in either knee in the past year (for which treatment was sought, or which interfered with function) or displayed abnormality on physical examination of the knee (flexion range of motion $(\mathrm{ROM}) \leq 125^{\circ}$, effusion, palpable warmth, ligamentous laxity) [3]. To answer the research questions on impact of osteoarthritis on balance 
an appropriate tools and scales: Postural sway-meter, Arthritis Impact Measurement Scale 2 Short Form, Index of Severity for Osteoarthritis of the knee, Fall Efficacy Scale were selected to study static postural sway, quality of life, degree of disability due to $\mathrm{OA}$ and perceived fear of fall were used respectively $[7,8]$.

A sample of 60 people aged 50-70 years of Kanpur city was taken for the study. A dully signed consent form was obtained from each participant. After taking the consent all the participants were assessed for inclusion and exclusion criteria. The participants who fulfill the inclusion and exclusion criteria their initial assessment was done regarding their demographic details, any present or past medical history, family history, surgical history, fall history and the pain assessment.

For evaluating balance deficits sway-meter was used. Postural sway was assessed in bipedal stance with bare feet (10 cm apart) on the firm surface on total 4 conditions: on floor with eyes open, eyes closed and on foam with open and eyes closed. Conditions were randomly presented and 3 trails of 30 seconds were conducted per condition, for 12 total trails per participants. Participants were instructed to stand still without talking as possible for a period of 30 seconds, with feet shoulderwidth apart and arms crossed over the chest while looking ahead and slightly down at a blank wall $1.5 \mathrm{~m}$ away $[9,10]$. Participants were offered a seat and rested for at least 1 minute in between trails. Testing under each condition was performed three times, with no practice permitted. If the loss of balance was imminent, testing was ceased for that particular condition. Tracings of the pen on graph paper yielded the following measures of postural sway: maximal sway in the

i. $\quad$ AP and

ii. Transverse or Medio-lateral directions and then

iii. Total sway area was calculated. A ruler was used to locate the outer borders of the AP and lateral directions used to determine the respective maximal sway measures. These variables were recorded under all the 4 conditions. The details required for responding to rest of the scales were given to the subject.

\section{Arthritis Impact Measurement Scale 2 Short Form}

Guillemin et al developed a short form of the AIMS2 (AIMS2SF) [11]. AIMS2-SF provides a comprehensive assessment of patients' health status comprising the dimensions physical limitation, symptom (reflecting perceived pain), social (reflecting social contacts), affect (reflecting mood), and work (reflecting the ability to work) [12]. AIMS2-SF contains 26 items, to reduce time effort and to increase acceptance among patients. In several validation studies, the AIMS2-SF has proven to be a reliable and valid instrument to assess Quality of Life of patients with rheumatoid arthritis and osteoarthritis and due to its comprehensiveness the AIMS2-SF gives insight into different dimensions of quality of life in osteoarthritis [13].

\section{Index of Severity for Osteoarthritis of the knee}

Lequesne et al. [14] developed an index of severity for knee osteoarthritis that is in the form of a self-administered questionnaire that assesses pain, function, and stiffness in the knee of osteoarthritis patients. The Lequesne Index has been extensively validated in osteoarthritis [14]. There are three sections to the index: Pain or discomfort, Maximum distance walked and Activities of daily living. Index of severity is equal to sum of all the parameters which form a total score ranging from 0- 24.

\section{Fall Efficacy Scale}

Tinetti et al. [15] developed the Falls Efficacy Scale (FES) to examine older adults [15], under the principle that fear of fall (FOF) could be measured by looking at fall-related self-efficacy, or a person's self-confidence in his or her ability to avoid falling while performing everyday activities (e.g. cleaning house, getting dressed, simple shopping). It is a 10 -question scale, with questions such as "How confident are you that you can clean the house without falling?" Subjects rate each question on a scale of 1 to 10 , and the scores are summed to give a total score between 0 and 100 . The total score of greater than 70 indicate that the person has a fear of falling [16].

Participants were given instructions to fill the scales, procedure was explained and the tests were conducted. The data was managed on assessments sheets and data collection forms. Analysis of data was done using SPSS (Statistical Package for Social Sciences) software version 17.0. For all statistical tests significance level was set at 0.05 .

\section{Results}

The study was done to find out the amount of balance deficits in the people with osteoarthritis. The balance deficit was measured by the postural sway-meter. The descriptive statistical analysis of the participants showed that the mean age in the control group $(n=30)$ was $56.1 \pm 5.97$ years, the mean age in the osteoarthritis $(n=30)$ group was $55.67 \pm 6.52$ years. The mean weight of control group was $62.2 \pm 9.53$ and the osteoarthritis group was $62.71 \pm 15.6$ (Table 1).

Table 1: Basic characteristics of the participants.

\begin{tabular}{|c|c|c|c|}
\hline Subjects & \multicolumn{3}{|c|}{ Characteristic } \\
\hline $\begin{array}{c}\text { Control group Age: } \\
\text { mean } \pm \text { SD N=30 }\end{array}$ & $56.1 \pm 5.97$ & $\begin{array}{c}\text { Control group } \\
\text { Weight : mean } \pm \text { SD } \\
\text { N=30 }\end{array}$ & $62.2 \pm 9.53$ \\
\hline $\begin{array}{c}\text { OA group } \\
\text { Age: mean } \pm \text { SD } \\
\text { N=30 }\end{array}$ & $55.67 \pm 6.52$ & $\begin{array}{c}\text { OA group Weight : } \\
\text { mean } \pm \text { SD N=30 }\end{array}$ & $62.71 \pm 15.6$ \\
\hline
\end{tabular}

SD: Standard deviation; N: Number of Participants; OA: Osteoarthritis. Balance Deficits

The data collected for anterio-posterior sway (AP), mediolateral/ transverse sway (T). Total sway area was calculated by multiplying the AP and T sway for both eyes open \& eyes 


\section{Orthopedics and Rheumatology Open Access Journal (OROAJ)}

closed conditions under all the four conditions. The result of the unpaired' $t$ ' test for comparison of the two groups: control group \& osteoarthritis group revealed significant difference in the total

Table 2: Mean total body sway in OA and control participants across all four testing conditions.

\begin{tabular}{|c|c|c|c|c|c|c|c|c|c|c|c|c|}
\hline \multirow{2}{*}{$\begin{array}{l}\text { Total } \\
\text { Sway }\end{array}$} & \multicolumn{3}{|c|}{ Floor eyes open } & \multicolumn{3}{|c|}{ Floor eyes closed } & \multicolumn{3}{|c|}{ Foam eyes open } & \multicolumn{3}{|c|}{ Foam eyes closed } \\
\hline & Mean & t- value & p-value & Mean & t-value & p-value & Mean & t-value & p-value & Mean & t-value & p-value \\
\hline $\begin{array}{l}\text { Control } \\
\text { Group }\end{array}$ & 236.65 & \multirow{2}{*}{$3.894^{* *}$} & \multirow{2}{*}{0.0001} & 213.13 & \multirow{2}{*}{$3.986^{* *}$} & \multirow{2}{*}{0.0001} & 450.02 & \multirow{2}{*}{$4.479 * *$} & \multirow{2}{*}{0.0001} & 708.38 & \multirow{2}{*}{$3.724^{* *}$} & \multirow{2}{*}{0.0001} \\
\hline $\begin{array}{c}\text { OA } \\
\text { Group }\end{array}$ & 461.13 & & & 659.18 & & & 1083.54 & & & 1395.33 & & \\
\hline
\end{tabular}

**= Significant at $\leq 0.01$ level, SD: Standard deviation; OA: Osteoarthritis.

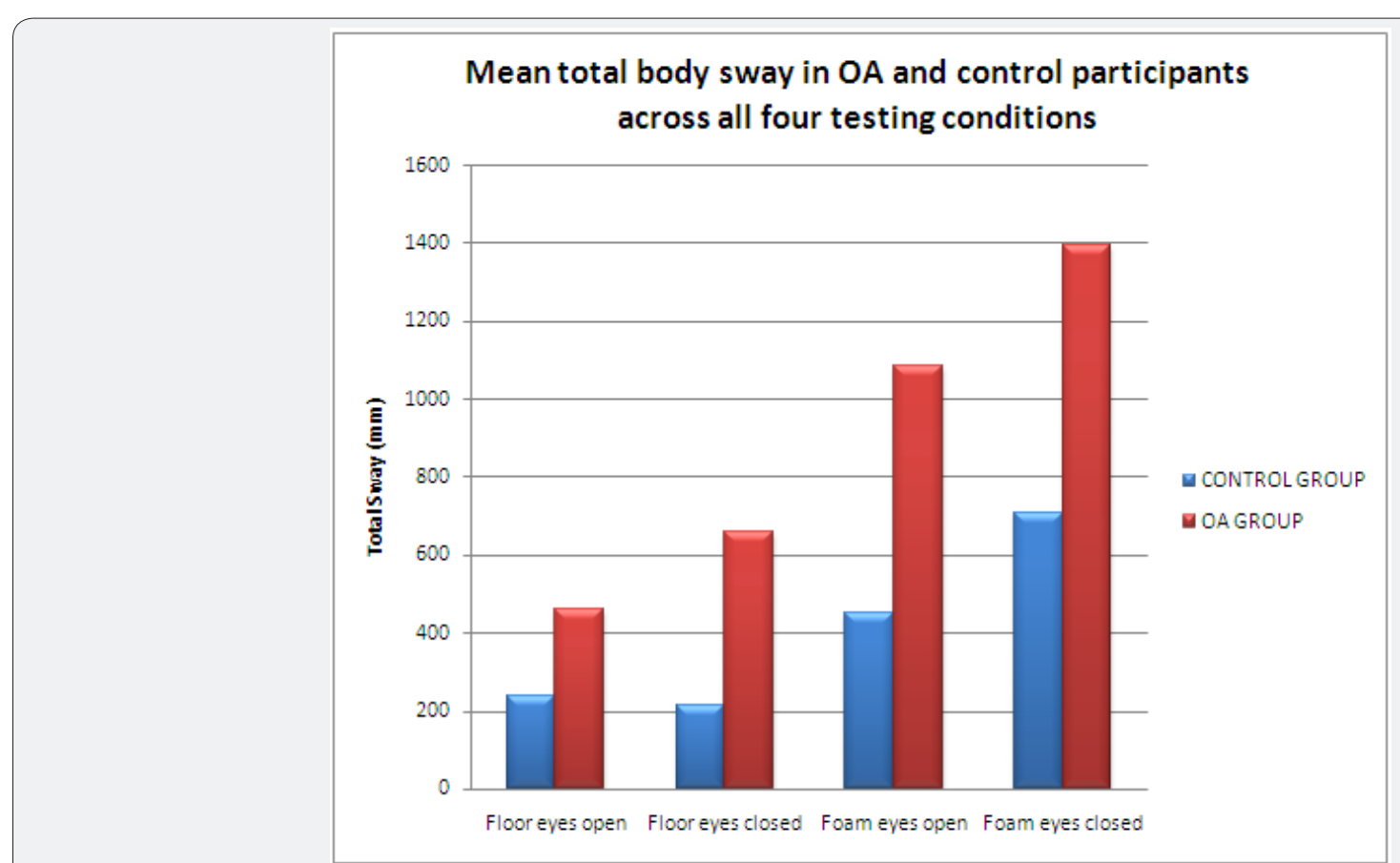

Figure 3 : Mean total body sway in OA and control participants across all four testing conditions.

i. $\quad$ ' $\mathrm{t}$ ' value $=3.89$ (eyes open on floor); ' $\mathrm{t}$ ' value $=3.98$ (eyes closed on floor)

ii. ' $t$ ' value $=4.479$ (eyes open on foam); ' $t$ ' value $=3.724$ (eyes open on foam)

\section{Impact of Balance Deficits on Quality of Life}

Pearson's correlational analysis showed significant co relation between balance deficits (under both eyes open and eyes close on floor condition) and quality of life.
a. $\mathrm{r}^{\prime}$ value $=.38^{* *} \mathrm{P}$ value $=.01($ eyes open $)$
b. $\mathrm{r}^{\prime}$ value $=.28 * \mathrm{P}$ value

\section{Impact of Balance Deficits on Knee Disability}

Pearson's co relational analysis showed significant correlation between balance deficits and degree of knee disability in both eyes open and eyes close on floor conditions in people of 50-70 years of age group.

i. $\quad r^{\prime}$ value $=.45^{* *}, \mathrm{P}$ value $=.001$ (eyes open on floor $)$ postural sway area under both eyes open and eyes closed on floor condition and on foam condition (Table 2) (Figure 3). 


\section{Orthopedics and Rheumatology Open Access Journal (OROAJ)}

relation with disability of knee due to osteoarthritis found to be highly significant.

' $r$ ' value $=.85^{* *}, \mathrm{P}$ value $=.00$

\section{Impact of Previous Falls on Perceived Fear of Fall}

Pearson's co relational analysis showed highly significant between participant's perceived fear of fall and their no. of fall in last 12 months.

$$
\text { ' } \mathrm{r} \text { ' value }=.86^{* *}, \mathrm{P} \text { value }=.00
$$

\section{Impact of Perceived Fear of Fall on their Quality of Life:}

Pearson's co relational analysis showed highly significant between participant's perceived fear of fall and their quality of life.

$$
\text { ' } r \text { ' value }=.40^{* *}, \mathrm{P} \text { value }=.00
$$

\section{Discussion}

The key finding of the present study is that the people with OA have significant balance deficits as compared to control group of same age group and other demographic details. The results of the study agree with Hinman RS et al. [3] findings which show that osteoarthritic population had significant balance deficits in both anterio posterior and transverse direction under eyes open and eyes close. The magnitude postural sway is the amount of movement of center of pressure (COP). Previous literature suggests that when the COP displacement falls outside the limits of stability (LOS) the person's balance get lost [17]. Hence greater the anterio-posterior or transverse sway more will be the chances of person to lose their balance [18-21]. Balance is one of the most important prerequisites for safe and independent mobility. The amount of anterio posterior and transverse or total sway in osteoarthritis and control group suggests that people with osteoarthritis significantly increase their sway displacement as compared to the people who had no symptoms of osteoarthritis [22-25]. The sway further increased as eyes closed condition was applied. This suggests that under eyes close condition where person has no visual feedback and he has to rely on their proprioceptive feedback more, people with osteoarthritis could not get the appropriate proprioceptive feedback hence their sway increased. In Ratzlaff CR et al. [26] also reported similar findings that people with knee injury have demonstrable neuromuscular impairments such as decreased quadriceps strength; poor lower limb positioning and proprioceptive deficits and impaired postural control.

These changes may leave the joint vulnerable to increased load and shear forces. They also cause accelerated process of joint degradation and cartilage degradation. This joint degeneration leads to increased severity of disability due to knee osteoarthritis [27-29]. The results of our study also confirms that increased postural sway or balance deficits strongly co-related with degree of knee disability. As the knee disability increases the balance deficits also increases. Results revealed that scores of balance deficits and "Index of Severity for Osteoarthritis for the Knee" strongly correlates with the quality of life scores on "Arthritis Impact Measurement Scale 2 Short Form" [30-32]. The balance deficits affect the mobility and this could possibly leads to social isolation and in turn affects the quality of life in people with osteoarthritis.

In the present study self reported questionnaire "Index of severity for osteoarthritis of knee by Lequesne et al. [33] was used to find out the degree of disability of knee. As researches which studied the clinical severity of $\mathrm{OA}$ and radiographical findings does not correlates. The secondary objective of the present study was to study the impact of severity of knee disability on various psycho-social factors. There is strong evidence that quality of life of patients suffering from chronic diseases is influenced by multiple factors as from instance support from family, the social situation, affect and mood [34]. There are few studies which have studied the even if the general practioners (GPs) is familiar with the patient he could easily miss some of the psychological factors. Hence the GP could easily miss few very important factors during giving his/her prescription [13]. Quality of Life must be checked while treating any patient with osteoarthritis.

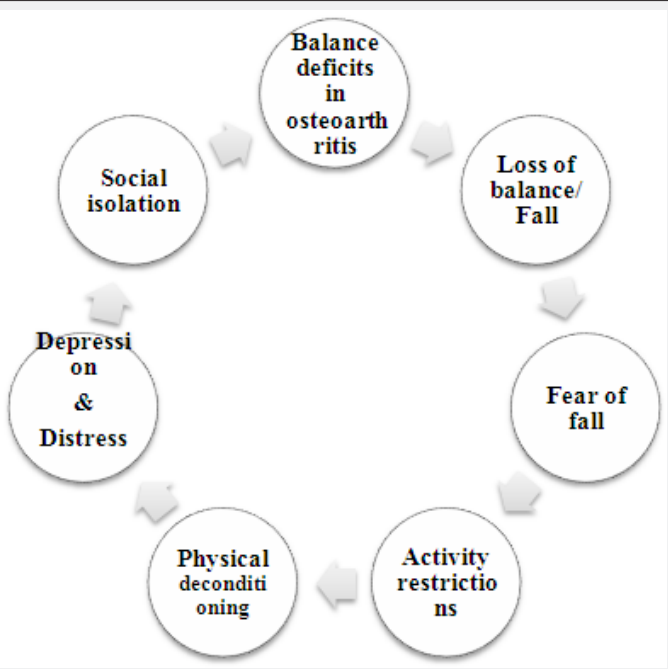

Figure 4: Viscous cycle created due to various physiological and psychological factors. 
Perceived fear of fall significantly correlates with quality of Life in elderly has been recognized as an important psychological factor associated with falls. Excessive fear of fall can lead to needless restriction in participation in physical and social activities, resulting in physical de-conditioning, social isolation, depression and distress. Its affect in osteoarthritis population was unknown. Results of the present study confirm that perceived fear of fall significantly affects the quality of life in people of osteoarthritis. The result of the study also confirmed that a previous episode of falls strongly correlate with person's perceived fear of fall. These physiological and psycho-social factors create a viscous cycle which is entirely interconnected. (Figure 4).

Hence the results of the present study could be concluded in clinical terms as: while attending any person with osteoarthritis possible balance deficits should be kept in mind and equal importance should be given to fear of fall, quality of life and their severity of knee osteoarthritis. Future studies are recommended to calculate the gender base differences and to calculate the amount of dynamic balance deficits in osteoarthritis. Present study can be done on larger population to get results which could provide us normative data for age related balance deficits assessed through postural sway meter.

\section{Conclusion}

The findings of the present study suggested that people with osteoarthritis presents with increase total (anterio-posterior and transverse) postural sway and hence has significant balance deficits. The secondary findings revealed that balance deficits and severity of knee osteoarthritis has a strong impact on person's quality of life and perceived fear of fall. The previous falls strongly correlates with person's perceived fear of fall.

\section{References}

1. Sengupta K, Alluri KV, Satish AR, Mishra S, Golakoti T, et al. (2008) A double blind, randomized, placebo controlled study of the efficacy and safety of 5-Loxin $\AA$ for treatment of osteoarthritis of the knee. Arthritis Res Ther 10(4): R85.

2. Ming-Chien Chyu, Veravon Bergen, Jean-Michel Brismee, Yan Zhang, James K Yeh, et al. (2011) Complementary and Alternative Exercises for Management of Osteoarthritis. Hindawi Publishing Corporation Arthritis 1-10.

3. Hinman RS, Bennell KL, Metcalf BR, Crossley KM, et al. (2002) Balance impairments in individuals with symptomatic knee osteoarthritis: a comparison with matched controls using clinical tests. Rheumatology 41(12): 1388-1394.

4. Bennell KL, Hinman RS, Metcalf BR, Buchbinder R, McConnell J, et al. (2005) Efficacy of physiotherapy management of knee joint osteoarthritis: a randomized, double blind, placebo controlled trial. Ann Rheum Dis 64(6): 906-912.

5. Afaf AM Shaheen, Khaled Ayad (2008) Impact of Chronic Osteoarthritis of Knee Joint on Postural Stability and Functional Mobility in Women. Bull Fac Ph Th Cairo Univ 13: 317-318.

6. Diana L Sturnieks, Ria Arnold, Stephen R Lord (2011) Validity and reliability of the Swaymeter device for measuring postural sway. BMC Geriatrics 11: 63.
7. Maria H Nilsson, Anna Maria Drake, Hagell P (2010) Assessment of fallrelated self-efficacy and activity avoidance in people with Parkinson's disease. BMC Geriatrics 10: 78.

8. Carol S Burckhardt, Kathryn L Anderson (2003) The Quality of Life Scale (QOLS): Reliability, Validity, and Utilization. Health and Quality of Life Outcomes 1: 60.

9. Renata Kochhann, Ana Luiza Camozzato, Cláudia Godinho, Maria Otília Cerveiro, Letícia MK Forster, et al. (2008) Cognitive complaints compared to performance on a mental state screening test in elderly outpatients. Dementia \& Neuropsychologia 2(1): 46-51.

10. Folstein MF, Folstein SE, McHugh PR (1975) Mini-Mental State: a practical method for grading the cognitive state of patients for the clinician. J Psychiatr Res 12(3): 189-198.

11. Taal E, Rasker JJ, Riemsma RP (2004) Sensitivity to change of AIMS2 and AIMS2-SF components in comparison to M-HAQ and VAS-pain. Ann Rheum Dis 63: 1655-1658.

12. Rosemann T, Laux G, Szecsenyi J (2007) Osteoarthritis: quality of life, comorbidities, medication and health service utilization assessed in a large sample of primary care patients. Journal of Orthopaedic Surgery and Research 2: 12 .

13. Rosemann T, Joos S, Koerner T, Szecsenyi J, Laux G, et al. (2006) Comparison of AIMS2-SF, WOMAC, x-ray and a global physician assessment in order to approach quality of life in patients suffering from osteoarthritis. BMC Musculoskeletal Disorders 7: 6.

14. Lequesne MG, Mery C, Samson M, Gerard P (1987) Indexes of severity for osteoarthritis of the hip and knee. Scand J Rheumatology Suppl 65: 85-89.

15. Legters K (2002) Fear of falling. Phys Ther 82(3): 264-272.

16. Gene Feder, Colin Crycr (2000) Guidelines for the prevention of falls in people over 65. BMJ 321: 1007-1011.

17. Yung-Hui Tien, Kuei-Fu Lin (2008) The Relationships between Physical Activity and Static Balance In elderly People. J Exerc Sci Fit 6(1): 21.

18. Burckhardt CS, Anderson KL (2003) The Quality of Life Scale (QOLS): Reliability, Validity, and Utilization. Health and Quality of Life Outcomes 1: 60 .

19. Chung-Wei Christine Lin, Deborah Taylor, Sita MA Bierma-Zeinstra, Christopher G Maher (2010) Exercise for Osteoarthritis of the Knee. Phys Ther 90(6): 839-842.

20. Chaurasia BD (2004) Joints of lower limb $4^{\text {th }}(e d n), 2: 143$.

21. Brotzman SB (1996) Handbook of Orthopaedic Rehabilitation. St Louis, Mosby, Missouri, USA, pp. 193-258.

22. Erin Hartigan, Michael Lewek, Lynn Snyder-Mackler (2011) The knee. Joint Structure and function: A Comprehensive Analysis 4: 393.

23. Sharon Parmet, Cassio Lynm, Richard M Glass (2003) Osteoarthritis of the Knee. The Journal of the American Medical Association 289(8): 1068.

24. Creamer P, Lethbridge-Cejku M, Hochberg MC (2000) Factors associated with functional impairment in symptomatic knee osteoarthritis. Rheumatology 39(5): 490-496.

25. Ming-Chien Chyu, Vera von Bergen, Jean-Michel Brismee, Yan Zhang, James K Yeh, et al. (2011) Complementary and Alternative Exercises for Management of Osteoarthritis. Hindawi Publishing Corporation Arthritis 364319: 10.

26. Charles R Ratzlaf, Matthew H Liang (2010) Prevention of injury-related knee osteoarthritis: opportunities for the primary and secondary prevention of knee osteoarthritis. Arthritis Research \& Therapy 12: 215. 
27. Winter DA (1995) Human balance and posture control during standing and walking. Gait \& Posture 3: 193-214.

28. Hobeika CP (1999) Equilibrium and balance in the elderly. Ear Nose Throat J 78: 558-566.

29. Sembulingam K, Prema Sembulingam (2010) Vestibular Apparatus. Essential of Medical Physiology 5: 880-888.

30. Lihavainen K, Sipilä S, Rantanen T, Sihvonen S, Sulkava R, et al. (2010) Contribution of Musculoskeletal Pain to Postural Balance in Community Dwelling People Aged 75 Years and Older. J Gerontol A Biol Sci Med Sci 65A(9): 990-996.

31. Stephen R Lord, Catherine Sherrington, Hylton B Menz (2001) Falls in older people. Cambridge University Press 2001: 3.

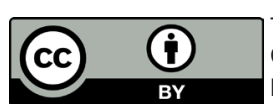

This work is licensed under Creative Commons Attribution 4.0 License

DOI: 10.19080/OROAJ.2018.11.555824
32. Kim Delbaere, Jacqueline CT Close, Henry Brodaty, Perminder Sachdev, Stephen R Lord (2010) Determinants of disparities between perceived and physiological risk of falling among elderly people: cohort study 341: 4165.

33. Lesley Fallow field (2009) What is quality of life? Health economics. Second (edn).

34.Zainal F Zakaria, Azman A Bakar, Hadzri M Hasmoni, Fauzi A Rani, Samiah A Kadir, et al. (2009) Health-related quality of life in patients with knee osteoarthritis attending two primary care clinics in Malaysia: a cross-sectional study. Asia Pacific Family Medicine 8(1): 10.

\section{Your next submission with Juniper Publishers will reach you the below assets}

- Quality Editorial service

- Swift Peer Review

- Reprints availability

- E-prints Service

- Manuscript Podcast for convenient understanding

- Global attainment for your research

- Manuscript accessibility in different formats

( Pdf, E-pub, Full Text, Audio)

- Unceasing customer service

Track the below URL for one-step submission https://juniperpublishers.com/online-submission.php 